\title{
Relations Between Executive Functions and Different Symptomatic Dimensions in Obsessive Compulsive Disorder ${ }^{1}$
}

\author{
Ana Cristina Pedron ${ }^{2}$ \\ Universidade Federal de Ciências \\ da Saúde de Porto Alegre, \\ Porto Alegre-RS, Brazil \\ Léia Gonçalves Gurgel \\ Universidade Federal de Ciências \\ da Saúde de Porto Alegre, \\ Porto Alegre-RS, Brazil
}

\author{
Ygor Arzeno Ferrão \\ Universidade Federal de Ciências \\ da Saúde de Porto Alegre, \\ Porto Alegre-RS, Brazil \\ Caroline Tozzi Reppold \\ Universidade Federal de Ciências \\ da Saúde de Porto Alegre, \\ Porto Alegre-RS, Brazil
}

\begin{abstract}
There is no consensus in the literature as to neuropsychological functioning, the severity of obsessive-compulsive symptoms (OCS) and the definitions of the OCS dimensions. We conducted a cross-sectional study investigating the relationship between executive function and OCS severity in the various dimensions, according to the Dimensional Yale-Brown Obsessive-Compulsive Scale criteria. We evaluated 28 patients with OCS, using eight neuropsychological instruments to evaluate executive function. We found that OCS severity in the contamination/cleaning dimension correlates negatively with executive function, inhibitory control and attentional control. Severity in the hoarding dimension correlated positively with cognitive flexibility, visual processing and logical reasoning, whereas it correlated negatively with the capacity to develop efficient complex problem-solving strategies. There was also a positive correlation between severity in the symmetry/ordering dimension and attentional control. Our findings suggest that the profile of executive function in OCD is defined by the severity of the various OCS dimensions.
\end{abstract}

Keywords: neuropsychology, neuropsychological tests, obsessive-compulsive disorder

\section{Relações Entre Funções Executivas e Diferentes Dimensões Sintomatológicas no Transtorno Obsessivo-Compulsivo}

\begin{abstract}
Resumo: Não há consenso na literatura quanto ao funcionamento neuropsicológico, a gravidade dos sintomas obsessivo-compulsivos (SOC) e as definições de suas dimensões. Realizou-se um estudo transversal para investigar a relação entre as funções executivas e a gravidade dos SOC nas várias dimensões, de acordo com os critérios dimensionais da Escala de Sintomas Obsessivo-compulsivos de Yale-Brown. Foram avaliados 28 pacientes com SOC, por meio de oito instrumentos de avaliação das funções executivas. A gravidade dos SOC, na dimensão contaminação/limpeza, correlacionou-se negativamente com as funções executivas controle inibitório e atenção. A gravidade da dimensão colecionismo foi positivamente correlacionada com a flexibilidade cognitiva, o processamento visual e o raciocínio lógico. Houve uma correlação negativa com a capacidade de desenvolver estratégias eficientes de resolução de problemas. Houve também uma correlação positiva entre a gravidade na dimensão simetria/ordenação e controle da atenção. Resultados sugerem que o perfil de funções executivas no TOC é definido pela gravidade das dimensões dos SOC.
\end{abstract}

Palavras-chave: neuropsicologia, testes neuropsicológicos, transtorno obsessivo-compulsivo

\section{Las Relaciones Entre las Funciones Ejecutivas y Diferentes Dimensiones Sintomáticas en Trastorno Obsesivo-Compulsivo}

\begin{abstract}
Resumen: No hay consenso en la literatura sobre el funcionamiento neuropsicológico, la gravedad de los síntomas obsesivo-compulsivos (SOC) y las definiciones de sus dimensiones. Fue llevado a cabo un estudio transversal para investigar la relación entre la función ejecutiva y la gravedad de la SOC en diversas dimensiones de estudio, de acuerdo con los criterios de trastorno obsesivo-compulsivo Escala de Síntomas Dimensión de Yale-Brown. Fueron evaluados 28 pacientes con SOC, utilizando ocho instrumentos para evaluar las funciones ejecutivas. La gravedad de los SOC en la dimensión contaminación / limpieza se correlaciona inversamente con la función ejecutiva control inhibitorio y atención. La gravedad de la dimensión de la recolección se correlacionó positivamente con la flexibilidad cognitiva, el procesamiento visual y el razonamiento lógico. Fue encontrada una correlación negativa con la capacidad de desarrollar estrategias eficaces para la resolución de problemas. Hubo también una correlación positiva entre la gravedad en la dimensión simetría / ordenación y control de la atención. Los resultados sugieren que el perfil de funciones ejecutivas en el TOC se define por la gravedad de las dimensiones de los SOC.
\end{abstract}

Palabras clave: neuropsicología, test neuropsicológico, trastorno obsesivo-compulsivo

\footnotetext{
1 Paper deriving from the primary author's master's dissertion under the second and fourth author's advice, defended in 2012 in the Graduate Program in Health Sciences at Universidade Federal de Ciências da Saúde de Porto Alegre.

2 Correspondence address:

Ana Cristina Pedron. Rua Sarmento Leite, 245, sala 117, Anexo 2. Centro. CEP 90050-170. Porto Alegre-RS, Brazil. E-mail: cris_pedron@hotmail.com
}

It remains unknown whether the deficits in executive function seen in patients with obsessive-compulsive disorder (OCD) constitute a stable characteristic or reflect the effects of specific symptoms of the disorder (Landeros-Weisenberger 
et al., 2010). Although no standardized definitions of the symptom dimensions of OCD have been established yet, a dimensional approach has been shown of significant clinical value, facilitating patient selection and the planning of treatment strategies (Landeros-Weisenberger et al., 2010). Developing a neuropsychological profile and determining the severity of obsessive-compulsive symptoms (OCS) can provide valuable information for more effective therapeutic interventions.

The delineation of neuropsychological profiles of executive functions in OCD patients might help identify predisposition or vulnerability to the development of the disorder, thus improving prevention and rehabilitation strategies. Neuropsychological investigations attempt to integrate the behavioral expressions of OCD with the particularities of higher cognitive functioning. The following OCS dimensions have been identified (Rosario-Campos et al., 2006): contamination/cleaning; symmetry; ordering; checking; unwanted (distasteful) thoughts, typically about sex, aggression or religion (blasphemy and conscientiousness); and hoarding. Factor analysis has identified four OCS dimensions: contamination/cleaning; obsessions/checking; symmetry/ordering; and hoarding. Some authors have even suggested that hoarding should be treated as a separate disorder, distinct from OCD (Mataix-Cols et al., 2010).

Studies attempting to associate the various OCS dimensions with neuropsychological and neurophysiological effects have produced inconclusive results. Mataix-Cols et al. (2004) found that hoarding was associated with hypofunction of the ventromedial prefrontal cortex (vmPFC), paralimbic regions, precentral gyrus and left prefrontal cortex. Lawrence et al. (2006) hypothesized that the hoarding and contamination/cleaning dimensions would correlate with functional losses in the vmPFC, resulting in impaired decision-making ability and a loss of skin conductance. The contamination/cleaning dimension has also been correlated with the function of the VmPFC and paralimbic regions, which are responsible for the perception of disgust (Mataix-Cols et al., 2004). Still, the review of Menzies et al. (2008) showed changes related to orbitofronto-striata areas in OCD.

Rauch et al. (1998) found an association between the contamination/cleaning dimension and blood flow to the bilateral anterior cingulate and left prefrontal cortex regions. Deficits in nonverbal memory have been associated with the symmetry/ordering dimension (Jang et al., 2010), greater severity of the dimension resulting in less cognitive flexibility (Lawrence et al., 2006), as assessed by the Wisconsin Card Sorting Test (WCST). Kim, Jang, and Kim (2009) found evidence of the neuropsychological aspects of subclinical OCD, and Shin et al. (2004) related to visuospatial memory. Vandborg, Hartmann, Bennedsen, Pedersen and Thomsen (2014) also observed that individuals with OCD show deficits in visuospatial memory in organizational skills. Especially among young people with OCD, deficits can be found in executive functioning and also in performance of non-verbal memory tasks (Lewin et al., 2014).
The reported effects specific OCS dimensions and their severity have on neuropsychological functioning include deficits in nonverbal memory and organizational strategies within the symmetry/ordering and obsessions/checking dimensions, respectively, which might indicate that visual memory and organizational capacity are influenced by various OCS dimensions (Jang et al., 2010). Tükel et al. (2012) reported that OCD patients have less capacity to understand abstract concepts, show impaired ability to shift between cognitive tasks and are more prone to distraction. In controlled studies employing the WCST, Menezes, Dias and Seabra (2011) found that OCD patients show impaired cognitive flexibility, while other authors did not. In a review article, Fontenelle (2001) found that patients with clinical or subclinical OCD show various deficits on neuropsychological tests. The author reported that patients with subclinical OCD perform more poorly on tests that evaluate the caudate-thalamic-frontal circuit, such as the WCST and the Stroop Test, than do those with clinical OCD. Patients with clinical OCD and those with subclinical OCD appear to be comparable in terms of the changes in executive function, including deficits of attentional control, working memory and cognitive flexibility. In addition, the author suggested that some of those deficits are associated with OCS severity and concluded that the impaired executive function seen in OCD is mainly related to changes in cognitive strategies and inhibitory control, as evidenced by the poor performance on the WCST. Bédard, Joyala, Godbouta, and Chantal (2009) and Sucolotti (2007), otherwise, found no significant association between OCS severity and the results of a neuropsychological assessment. Unfortunately, no results were described relating the severity of the OCS specific dimensions with neuropsychological tests. The lack of evidence that pharmacological treatment improves the performance on neuropsychological tasks may indicate that total scores of the instruments that measure OCD as a whole may confirm that severity measured in that way may not be the best alternative (Roh et al., 2005).

In view of the facts presented above, we designed the present study to investigate the association between executive functions and OCS severity in the following specific dimensions, as evaluated by the Dimensional Yale-Brown Obsessive-Compulsive Scale (DY-BOCS): aggression; sexual/religious obsessions; symmetry/ordering; contamination/cleaning; and hoarding. This scale is composed of a self-reported part and one that should be applied by specialists. The DY-BOCS is presented as a valid tool for assessing the severity of OCD symptoms (Rosario-Campos et al., 2006).

\section{Method}

\section{Participants}

Between January and October 2011, we evaluated a sample of patients between 18 and 65 years of age who had been diagnosed with OCD according to the Diagnostic and 
Statistical Manual of Mental Disorders, Fourth Edition, Text Revision - DSM-IV-TR (American Psychiatric Association [APA], 2000). The patients were recruited among those under treatment at the Anxiety Clinic of the President Vargas Hospital for Mothers and Children, as well as from private clinics, in the city of Porto Alegre, Brazil. We invited 62 patients to participate in the study. Of those 62 patients, 34 were excluded: 31 because they declined to participate; one because of current illicit drug use; one because of extremely low intellectual capacity, as evaluated by the Wechsler Abbreviated Scale of Intelligence (WASI); and one because of extreme OCS severity, which precluded evaluation of the patient. Therefore, the final sample comprised 28 patients.

Although the new edition of the DSM - DSM-V (APA, 2013) included the accumulation disorder as an entity, at the time of data collection, we used the DSM-IV-TR. Therefore, in this study, only patients with OCD were included who had, among other symptoms, accumulation. We did not include patients with Accumulation Disorder and without OCD.

The mean age was 38.6 years $(S D=11.9$ years $)$, and the mean number of years of schooling was $5.8(S D=2.6)$. Of the 28 patients, 13 (46.4\%) were female. Six patients (21.4\%) were unemployed. Five patients $(17.9 \%)$ had a family history of OCD. The mean BDI and BAI scores were $15.4(S D=8.4)$ and $25.9(S D=6.6)$, respectively. All patients were taking selective serotonin reuptake inhibitors: fluvoxamine, in 13 (46.4\%); fluoxetine, in 6 (21.4\%); paroxetine, in $4(14.3 \%)$; sertraline, in $3(10.7 \%)$; and clomipramine, in $2(7.1 \%)$. Seven $(25 \%)$ of the patients were using benzodiazepines, the most common being clonazepam, which $4(14.3 \%)$ patients were using. Six patients $(21.4 \%)$ were taking antipsychotics, the most common being risperidone, which 4 patients (14.3\%) were taking. Other medications patients in the sample used included divalproex sodium, in $3(10.7 \%)$; lithium carbonate, in 3 (10.7\%); and pregabalin, in $1(3.6 \%)$.

\section{Instruments}

Structured Clinical Interview for DSM-IV Axis I Disorders. It is used to reach or confirm a diagnosis of OCD and to identify comorbid axis I disorders (First, Spitzer, Gibbon, \& Williams, 1997). In the present study, we used a Portuguese-language version of the SCID-I validated for use in Brazil (Del-Ben et al., 2001). This instrument has good inter-rater reliability (Del-Ben et al., 2001) and presents an appropriate Kappa coefficient $(\mathrm{Kw}=.83)$. The reliability was significant for $\operatorname{mood}(\mathrm{K}=.87)$, psychotic $(\mathrm{K}=.90)$ and substance-related disorders.

Dimensional Yale-Brown Obsessive-Compulsive Scale (DY-BOCS). It is used to identify OCS and evaluate the severity of specific OCS dimensions (Rosario-Campos et al., 2006). It consists of 88 items grouped into six dimensions: aggression; sexual/religious; contamination/cleaning; symmetry/ordering; hoarding; and miscellaneous. The clinical severity of each dimension - current and previous (during the worst episode) - is evaluated on the basis of three aspects: symptom frequency, discomfort and interference with activities of daily living. For a given dimension, the maximum score is 15 points ( $0-5$ points for each aspect). The DY-BOCS also evaluates overall OCD severity and shows a very high correlation with the Y-BOCS score $(r=.96$, $p<.01)$ and with the OCI $(r=.61, p<.01)$.

Yale-Brown Obsessive Compulsive Scale (Y-BOCS; Goodman et al., 1989). This scale was translated for Brazil and consists of three steps, checking the intensity, severity and extent of the disorder. It consists of ten items with scores ranging from 0 to 4 points. Five of the questions aimed at assessing the severity of obsessive symptoms and the other the severity of compulsive symptoms. This scale allows to clinically evaluate the overall severity of obsessive-compulsive symptoms (Miguel et al., 2008). Cronbach's alpha coefficients range between .76 and .80, showing high psychometric qualities (Goodman et al., 1989; Moritz et al., 2002).

WASI. It is designed to evaluate intelligence and is composed of four subtests: Vocabulary, Similarities, Matrix Reasoning and Block Design. The sums of the scores on the first two subtests and last two subtests are used to calculate the verbal IQ and performance IQ, respectively, whereas the full-scale IQ is calculated by summing the scores of all four subtests. The WASI presents evidence of convergent validity when correlated with other scales that assess intelligence, in the American version, ranging between .69 and .72. For adults, precision coefficients ranged from .84 to .98 . The WASI has been translated into Portuguese and properly validated for use in Brazil (Heck et al., 2009).

Digits Forward and Backward and Letter-Number Sequencing: components of the Wechsler Adult Intelligence Scale - WAIS-III (Wechsler, 1997). The Digit Span subtest score is derived from the sum of two separate scores (digit span under forward and backward recall conditions). The digit span forward task evaluates attentional amplitude and immediate auditory memory, whereas the digit span backward task provides a good measure of working memory, because it requires that the information be not only retained but also manipulated. The LNS subtest, which increases in complexity as it advances, consists in the examiner reading a random combination of numbers and letters, which the subject is expected to repeat. However, the subject must repeat the numbers in ascending order and, then, the letters in alphabetical order. It is a test of attentional control and working memory. These subtests require sequencing processes and planning, as well as visualization and manipulation of the stimuli. Iverson (2001) observed that most of the subtests of the WAIS-III showed excellent internal consistency (.85-.99) in the literature.

Rey Complex Figure Test. Assesses visuospatial organizational skills; the development of planning and implementation strategies; and nonverbal memory. The RCFT is widely used internationally, both in research and in clinical practice. Subjects are required to use strategies in copying 
and subsequently reproducing figures, their performance on those tasks being considered a measure of executive function. The RCFT consists of three test conditions: Copy, Immediate Recall and Delayed Recall. In the present study, we used a Portuguese-language version of the RCFT that has been validated for use in Brazil. In the internal consistency analysis, the Cronbach's alpha coefficient was .86 for copying and .81 for memory. Reliability was assessed by the test-retest method and the coefficient was .76. An inter-expert review showed agreement on all items (Oliveira \& Rigoni, 2010).

Phonemic Verbal Fluency Test. It is one of the most widely used instruments for the evaluation of executive function, specifically phonemic verbal fluency (Drake \& Torralba, 2007). In the FAS, the subject is given 60 seconds to say as many words as possible that start with the letters F, A or S, excluding proper nouns, verb conjugations and alternate forms of words already given. The total score is simply the number of words generated. It is considered a test that involves the activation aspect of executive function - production, cognitive flexibility and self-monitoring (Shigaeff, Miotto, Lucia, \& Scaff, 2011). The test has good reliability and a Cronbach's alpha coefficient of .833 (Tombaugh et al., 1999).

Stroop Color-Word Test. Used the Brazilian Portugueselanguage version devised by Golden (1978). The Stroop Test is a measure of attentional control (selective attention) and inhibitory control that involves the naming of words and colors. It evaluates the subject's ability to change a response, according to demand, and to inhibit a usual response in favor of an unusual response. Therefore, it measures selective attention and executive function. In this task, in which the memory demand is minimal, individuals are required only to select relevant information in order to complete the task. Presents psychometric adequacy for the Brazilian population and good temporal reliability $(r>.80)$ (Connor et al., 1988).

Go No-Go Task. It can be used to identify impairment in inhibitory mechanisms (Grafman, 1999). It is an emission and suppression paradigm of responses in which the subject should give the answer when presented with a particular group of stimuli and should suppress it when presented with different stimuli. Tasks that use this paradigm provide measures of action based on error, omission and reaction time. Errors are related to inhibitory control, whereas omissions are related to attentional control. If reaction time is defined as the time to the stop-signal, it can also evaluate inhibitory control. In the present study, we used a computerized version in which, once per second, several letters of various colors appeared on the computer screen. The subject was instructed to press the space bar on the computer keyboard when any letters appeared, except when the letter "O" appeared in blue or the letter "E" appeared in pink. In the test-retest, the correlation observed ranged from $r=.57(p<.01)$ to $r=.83$ $(p<.001)$, indicating high reliability and psychometric adequacy (Langenecker et al., 2007).

WCST. It has been considered the gold standard for evaluating executive function and has now been translated to Portuguese and adapted for use in Brazil (Cunha et al., 2005). In this test, 128 cards are presented to the subject, one at a time. The subject is asked to match each new card to one of four target cards. Cards may be matched according to number, color, or shape; however, matching criteria are not explicitly explained to the participant. The participant must infer the correct dimension on which to sort by evaluating the examiner's feedback (correct/incorrect) on each attempted match. After a certain number of correct responses, the sorting criterion is changed (e.g., from color to shape) unannounced to the participant, and the participant must learn the new contingency by trial and error. Perseverative errors (PE) result when a participant fails to adjust to the new sorting rule. We used the number of PEs as an index of the executive function of set shifting. The WCST presents psychometric quality, with appropriate correlations in the test-retest $(r=.50, p<.01)$ (Ettenhofer, Hambrick, \& Abeles, 2006).

Obsessive-Compulsive Inventory - Revised (OCI-R). The OCI-R is a short version of the OCD and a self-report scale for assessing symptoms of Obsessive-Compulsive Disorder (OCD). It consists of 18 questions a person endorses on a 5-point Likert scale (Foa et al., 2002). The instrument shows good internal consistency among patients with $\operatorname{OCD}(\alpha=.83)$ and anxiety disorders $(\alpha=.88)$. The itemtotal correlation was adequate $(M=.51$, range $=.37-.65)$ (Abramowitz \& Deacon, 2006).

\section{Procedure}

Data collection. Study participants were interviewed by psychologists or psychiatrists trained in achieving satisfactory inter-rater reliability in the use of diagnostic instruments, via the Brazilian Research Consortium on Obsessive-Compulsive Spectrum Disorders (Miguel et al., 2008). The neuropsychological evaluation was performed by a trained neuropsychologist, in a single session of approximately four hours. All rules of the instruments were complied with. The instruments were always applied in the same order. Interference between the constructs was avoided.

Data analysis. To characterize the sample, descriptive and inferential statistics were conducted. Tests with normal distribution were analyzed using Pearson's correlation coefficient, and the results are presented as mean and standard deviation $(S D)$ or medians (minimum and maximum scores). Tests that showed non-parametric distribution were analyzed using Spearman's correlation coefficient, and the results are presented as median and interquartile range. Control of parametric distribution was proceeded by the Shapiro-Wilk test. To construct the clinical profile, each DY-BOCS dimension was evaluated as a categorical variable (presence or absence of specific symptoms) and as a continuous variable (severity of specific symptoms). For the other instruments, we analyzed the raw scores, except in the case of the RCFT, the scores of which have been standardized for Brazilian subjects. 
The means of the variables with normal distribution (according to Shapiro-Wilk test) were compared using Student's $t$-test. For non-normal variables, medians were compared using Mann-Whitney's $U$-test. We compared the means and medians splitting the dataset according to possessing (patient scored more than ' 1 ') or not (patient scored ' 0 ') each specific dimension of the DY-BOCS. This comparison was performed only for the neuropsychological tests on which the scores correlated significantly with any of the DY-BOCS dimensions. All statistical analyses were performed using the Statistical Package for the Social Sciences, version 15.0 (SPSS Inc, Chicago, IL, USA). The level of statistical significance was set at $5 \%$ for all tests.

\section{Ethical Considerations}

The study received approval from the Research Ethics Committees of the Hospital Materno-Infantil Presidente Vargas (Project no. 9/2011) and the Universidade Federal de Ciências da Saúde de Porto Alegre (Protocol no. 559/09).

\section{Results}

The mean OCI score was $31.0(S D=14.9)$, and the mean total Y-BOCS score was $19.8(S D=8.3)$. The mean Y-BOCS subscale scores were $8.9(S D=4.1)$ for obsessions and 10.9 $(S D=5.0)$ for compulsions. The mean total DY-BOCS score was $16.5(S D=7.0)$. Figure 1 shows the prevalence and severity of OCS dimensions according to the DY-BOCS.

We performed a correlation analysis of the BDI and BAI scores in comparison with the scores on the WASI and RCFT, the two neuropsychological instruments for which the scores have been standardized for Brazilian subjects. Between the BDI score and the RCFT recovery percentile (immediate recall), we found a moderate correlation $(r=.50$, $p \leq .01)$. There were no other significant correlations.

The raw scores on the WASI subtests Matrix Reasoning and Block Design were found to correlate negatively with the

Prevalence and mean (SD) severity of DY-BOCS Dimensions

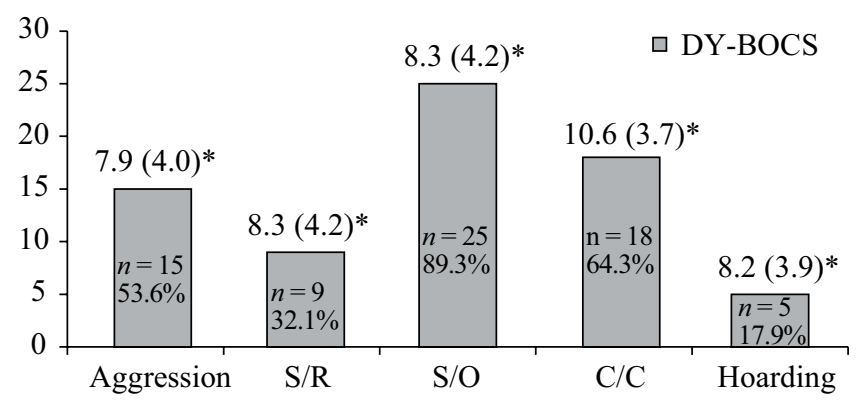

Figure 1. Prevalence and severity of obsessive-compulsive symptoms in the Dimensional Yale-Brown Obsessive-Compulsive Scale (DY-BOCS) dimensions: aggression, sexual/religious (S/R), symmetry/ordering (S/O), contamination/cleaning $(\mathrm{C} / \mathrm{C})$ and hoarding. ${ }^{*} M(S D)$. severity of contamination/cleaning symptoms. Consequently, the raw score for performance IQ was lower among subjects presenting the contamination/cleaning dimension. As seen in Table 1, there was a strong positive correlation between the severity of hoarding symptoms and the raw score on the Matrix Reasoning subtest. When we considered the WASI percentiles according to the norms established for the Brazilian population, we found a statistically significant negative correlation between verbal IQ and the severity of aggression and obsessive compulsions. In addition, there was a trend toward higher performance IQ and total IQ in OCD patients without obsessive symptoms of aggression or related compulsions.

Regardless of the DY-BOCS dimension, OCS severity did not correlate significantly with the raw scores on the WAIS-III subtests Digit Span Forward, Digit Span Backward and LNS, nor with the raw scores on the FAS or Stroop Test. The severity of OCS related to aggression and compulsions, however, was found to correlate positively with figure recall time and time to copy the figure on the RCFT, the correlation being stronger for the former. In addition, when comparing the results with the RCFT reference values established for the Brazilian population, the percentile for time to copy the figure was significantly higher for OCD patients who presented the sexual/religious dimension than for those who did not. There was also a significant difference in RCFT figure recall time, the percentile being highest for OCD patients presenting the symmetry/ordering dimension.

Table 2 shows the correlations between DY-BOCS dimension severity and the raw scores on the go/no-go task and the WCST. We found that OCS severity in the symmetry/ordering dimension correlated positively with all of those scores. Severity in the contamination/cleaning correlated positively with the raw scores for errors of omission and commission on the go/no-go task. On the WCST, the total number of correct responses correlated negatively with OCS severity in the contamination/cleaning dimension. There was also a negative correlation between the presence of the hoarding dimension and the raw "learning to learn" score on the WCST. Table 3 shows the mean scores for the various neuropsychological instruments.

\section{Discussion}

The aim of this study was to determine whether executive function is related to OCS severity in the various dimensions defined in the DY-BOCS. Although a number of studies have suggested that OCD patients show impaired executive function in comparison with healthy controls (Tükel et al., 2012), there is some debate about whether the neuropsychological deficits associated with OCD would be of primary origin or result from differences in OCD symptomatology (Bannon, Gonsalvez, Croft, \& Boyce, 2006). Our findings may show that greater OCS severity in the contamination/cleaning dimension results in poorer planning, organization, visual perception, cognitive 
Table 1

Correlations between Symptom Severity in the Various Dimensions (of Dimensional Yale-Brown Obsessive-Compulsive Scale - DY-BOCS) of Obsessive-Compulsive Disorder and the Results Obtained With Neuropsychological Evaluation Instruments

\begin{tabular}{|c|c|c|c|c|c|c|}
\hline \multirow{2}{*}{ Instrument } & & \multicolumn{5}{|c|}{ Obsessive-compulsive symptom dimension (DY-BOCS) } \\
\hline & & Aggression & Sexual/religious & Symmetry/ordering & Contamination/cleaning & Hoarding \\
\hline \multirow[t]{2}{*}{ WASI Vocabulary } & $r$ & -.19 & -.30 & -.21 & -.36 & .33 \\
\hline & $p$ & .48 & .43 & .29 & .13 & .58 \\
\hline \multirow[t]{2}{*}{ WASI Block Design } & $r$ & -.13 & .09 & -.20 & $-.53 *$ & .28 \\
\hline & $p$ & .64 & .80 & .31 & .02 & .64 \\
\hline \multirow[t]{2}{*}{ WASI Similarities } & $r$ & -.06 & -.34 & -.23 & -.39 & .12 \\
\hline & $p$ & .82 & .35 & .25 & .10 & .84 \\
\hline \multirow[t]{2}{*}{ WASI Matrix Reasoning } & $r$ & -.10 & -.17 & -.29 & $-.57 *$ & $.94^{*}$ \\
\hline & $p$ & .71 & .64 & .15 & .01 & .01 \\
\hline \multirow[t]{2}{*}{ WASI verbal IQ } & $r$ & -.23 & -.29 & -.22 & -.35 & .31 \\
\hline & $p$ & .40 & .43 & .28 & .15 & .60 \\
\hline \multirow[t]{2}{*}{ WASI performance IQ } & $r$ & -.24 & -.08 & -.27 & $-.52 *$ & .63 \\
\hline & $p$ & .38 & .82 & .18 & .02 & .25 \\
\hline \multirow[t]{2}{*}{ WASI total IQ } & $r$ & -.24 & -.19 & -.26 & -.46 & .51 \\
\hline & $p$ & .38 & .61 & .19 & .05 & .31 \\
\hline \multirow[t]{2}{*}{ RCFT (copy) } & $r$ & -.01 & -.35 & -.12 & -.15 & .51 \\
\hline & $p$ & .95 & .35 & .55 & .54 & .37 \\
\hline \multirow[t]{2}{*}{ RCFT (recall) } & $r$ & -.19 & .23 & -.22 & -.40 & .22 \\
\hline & $p$ & .48 & .53 & .28 & .09 & .71 \\
\hline \multirow[t]{2}{*}{ RCFT (copy time) } & $r$ & $.55^{*}$ & .21 & .31 & .24 & -.44 \\
\hline & $p$ & .03 & .58 & .12 & .33 & .45 \\
\hline \multirow[t]{2}{*}{ RCFT (recall time) } & $r$ & $.64 * *$ & .43 & .28 & .16 & -.44 \\
\hline & $P$ & .01 & .24 & .16 & .52 & .45 \\
\hline \multirow[t]{2}{*}{ WAIS-III DSF } & $r$ & .05 & -.36 & -.33 & -.37 & .34 \\
\hline & $p$ & .85 & .34 & .10 & .12 & .56 \\
\hline \multirow[t]{2}{*}{ WAIS-III DSF (maximum span) } & $r$ & .10 & -.32 & -.35 & -.32 & .48 \\
\hline & $p$ & .69 & .40 & .07 & .19 & .40 \\
\hline \multirow[t]{2}{*}{ WAIS-III DSB } & $r$ & -.13 & -.08 & -.17 & -.42 & .51 \\
\hline & $p$ & .62 & .82 & .40 & .08 & .37 \\
\hline \multirow[t]{2}{*}{ WAIS-III DSB (maximum span) } & $r$ & -.19 & -.20 & -.22 & -.46 & .51 \\
\hline & $p$ & .49 & .59 & .29 & .05 & .37 \\
\hline \multirow[t]{2}{*}{ WAIS-III DSF and DSB } & $r$ & -.04 & -.24 & -.26 & -.41 & .39 \\
\hline & $p$ & .88 & .51 & .20 & .09 & .51 \\
\hline \multirow[t]{2}{*}{ WAIS-III LNS (total score) } & $r$ & -.08 & -.16 & -.20 & -.35 & .70 \\
\hline & $p$ & .76 & .67 & .32 & .14 & .18 \\
\hline \multirow[t]{2}{*}{ FAS (total score) } & $r$ & -.44 & -.22 & -.31 & -.32 & .75 \\
\hline & $p$ & .09 & .56 & .12 & .18 & .14 \\
\hline \multirow[t]{2}{*}{ Stroop trial 1} & $r$ & -.20 & .15 & -.28 & -.27 & .41 \\
\hline & $p$ & .46 & .69 & .16 & .26 & .49 \\
\hline \multirow[t]{2}{*}{ Stroop trial 2} & $r$ & .02 & -.02 & -.36 & $-.51 *$ & -.31 \\
\hline & $p$ & .92 & .95 & .07 & .03 & .61 \\
\hline \multirow[t]{2}{*}{ Stroop trial 3 (Stroop effect) } & $r$ & -.22 & .20 & .21 & .32 & .37 \\
\hline & $p$ & .42 & .60 & .31 & .19 & .53 \\
\hline
\end{tabular}

Note. DY-BOCS = Dimensional Yale-Brown Obsessive-Compulsive Scale; WASI = Wechsler Abbreviated Scale of Intelligence; RCFT = Rey Complex Figure Test; WAIS-III = Wechsler Adult Intelligence Scale, third edition; LNS = Letter-Number Sequencing; DSF = Digit Span Forward; DSB = Digit Span Backward; FAS = phonemic verbal fluency test.

$* p<.05$ (Pearson's). $* * p<.01$ (Pearson's). 
Pedron, A. C., Ferrão, Y. A., Gurgel, L. G., \& Reppold, C. T. (2015). Executive Function and OCD.

Table 2

Correlations Between Symptom Severity in the Various Dimensions (of Dimensional Yale-Brown Obsessive-Compulsive Scale - DY-BOCS) of Obsessive-Compulsive Disorder and the Results Obtained With the Go/No-Go Task and the Wisconsin Card Sorting Test

\begin{tabular}{|c|c|c|c|c|c|c|}
\hline \multirow{2}{*}{ Instrument } & & \multicolumn{5}{|c|}{ Obsessive-compulsive symptom dimension (DY-BOCS) } \\
\hline & & Aggression & $\mathrm{S} / \mathrm{R}$ & $\mathrm{S} / \mathrm{O}$ & $\mathrm{C} / \mathrm{C}$ & Hoarding \\
\hline \multirow[t]{2}{*}{ Go/no-go omission } & $p$ & .13 & -.20 & $.40^{*}$ & $.53 *$ & -.78 \\
\hline & $\rho$ & .64 & .59 & .04 & .02 & .11 \\
\hline \multirow[t]{2}{*}{ Go/no-go commission } & $p$ & .14 & .31 & .27 & $.48^{*}$ & -.28 \\
\hline & $\rho$ & .61 & .41 & .19 & .04 & .64 \\
\hline \multirow[t]{2}{*}{ WCST $n$ of tests administered } & $p$ & .15 & .43 & .05 & .12 & .12 \\
\hline & $\rho$ & .57 & .24 & .78 & .62 & .84 \\
\hline \multirow[t]{2}{*}{ WCST $n$ of correct responses } & $p$ & -.08 & -.19 & -.16 & $-.47 *$ & .67 \\
\hline & $\rho$ & .75 & .62 & .45 & .04 & .21 \\
\hline \multirow[t]{2}{*}{ WCST $n$ of correct responses } & $p$ & .18 & .65 & .14 & .22 & -.22 \\
\hline & $\rho$ & .51 & .08 & .51 & .36 & .71 \\
\hline \multirow[t]{2}{*}{ WCST $n$ of perseverative responses } & $p$ & .21 & .45 & .21 & .29 & .11 \\
\hline & $\rho$ & .45 & .22 & .30 & .24 & .85 \\
\hline \multirow[t]{2}{*}{ WCST $n$ of perseverative errors } & $p$ & .18 & .46 & .14 & .20 & .11 \\
\hline & $\rho$ & .51 & .21 & .50 & .41 & .85 \\
\hline \multirow[t]{2}{*}{ WCST $\%$ of perseverative errors } & $p$ & .19 & .47 & .13 & .22 & .11 \\
\hline & $\rho$ & .48 & .19 & .53 & .37 & .85 \\
\hline \multirow[t]{2}{*}{ WCST $n$ of nonperseverative errors } & $p$ & .14 & .28 & -.11 & -.10 & -.05 \\
\hline & $\rho$ & .61 & .45 & .58 & .66 & .92 \\
\hline \multirow[t]{2}{*}{ WCST answer percentage of conceptual level } & $p$ & -.15 & -.41 & -.18 & -.27 & .22 \\
\hline & $\rho$ & .58 & .26 & .38 & .26 & .71 \\
\hline \multirow[t]{2}{*}{ WCST $n$ of categories completed } & $p$ & -.11 & -.33 & -.17 & -.43 & -.17 \\
\hline & $\rho$ & .69 & .34 & .42 & .07 & .77 \\
\hline \multirow[t]{2}{*}{ WCST $n$ of tests to complete the 1 st class } & $p$ & .07 & .10 & .24 & .23 & -.62 \\
\hline & $\rho$ & .78 & .79 & .25 & .34 & .26 \\
\hline \multirow[t]{2}{*}{ WCST failure to maintain context } & $p$ & .07 & -.28 & -.01 & .06 & .79 \\
\hline & $\rho$ & .80 & .48 & .93 & .80 & .11 \\
\hline \multirow[t]{2}{*}{ WCST learning to learn } & $p$ & .11 & -.10 & .28 & .09 & $-.89 *$ \\
\hline & $\rho$ & .75 & .87 & .28 & .76 & .04 \\
\hline
\end{tabular}

Note. DY-BOCS = Dimensional Yale-Brown Obsessive-Compulsive Scale; WCST $=$ Wisconsin Card Sorting Test; S/R = sexual/religious; $\mathrm{S} / \mathrm{O}=$ symmetry/ordering; $\mathrm{C} / \mathrm{C}=$ contamination/cleaning.

$* p<.05$ (Spearman's). $* * p<.01$ (Spearman's).

flexibility and processing speed, as evaluated by the WASI subtests Matrix Reasoning and Block Design. We also found that OCD patients presenting contamination/cleaning had deficits in attentional and inhibitory control, as evidenced by errors of omission and commission, respectively, on the go/no-go task. The fact that these deficits in executive function are associated with this dimension might explain the difficulty these patients have in changing or avoiding the thoughts and behaviors that are the core features of OCD (APA, 2000).

On the RCFT, the severity of OCS in the aggression dimension resulted in longer times to copy the figure, to recall the figure and to reproduce the figure from memory, suggesting impaired planning ability. The problems of executive planning in OCD might account for the difficulties in spatial organization and, in turn, exert a secondary effect on immediate memory.
The authors stated that such memory deficits seem to be more closely related to the organizational skills needed to plan a task than to memory (Pena-Garijo, Ruipérez-Rodríguez, \& Barros-Loscertales, 2010; Pena \& Vale, 2010). In the present study, however, we found a better percentile in copying, as OCD patients who presented the sexual/religious dimension performed better on the RCFT figure copying task than did those who did not present that dimension, the former producing copies that were more accurate and more well-structured. The differences between the OCD patients in the results found between the aggression dimension and those presenting the sexual/religious dimension underscores the heterogeneity of OCD (Mataix-Cols et al., 2010) and the importance of studying the various dimensions of the disorder, as well as that of considering the severity of each dimension and the possible etiological differences among them (Fontenelle, 2001; Jang et al., 2010; Landeros-Weisenberger et al., 2010). 
Table 3

Descriptive Statistics of the Performance of Obsessive-Compulsive Patients $(n=28)$ on Neuropsychological Evaluations

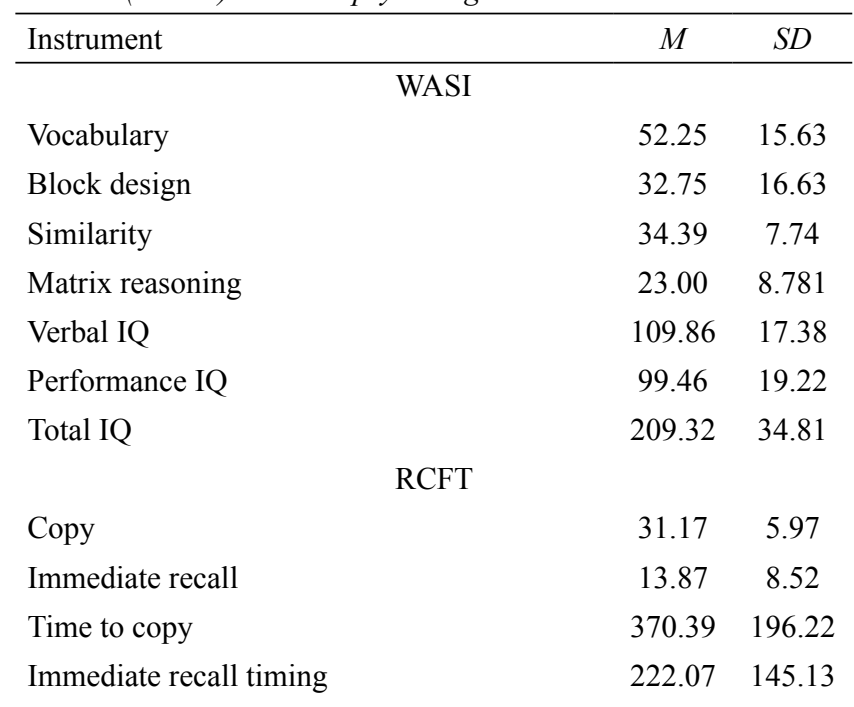

WAIS-III

DSF

$7.79 \quad 2.75$

DSF (maximum span)

$6.04 \quad 3.15$

DSB

$13.89 \quad 5.45$

LNS

$9.79 \quad 4.33$

FAS

$37.57 \quad 11.66$

Go/no-go task

Omission

Commission

$8.93 \quad 14.76$

$6.07 \quad 5.67$

WCST

\begin{tabular}{|c|c|c|}
\hline total $n$ of correct responses & 63.44 & 13.33 \\
\hline total $n$ of incorrect responses & 41.96 & 29.89 \\
\hline Perseverative responses & 33.37 & 32.23 \\
\hline Perseverative errors & 24.00 & 23.90 \\
\hline Percentage of perseverative errors & 20.26 & 17.71 \\
\hline No perseverative errors & 17.81 & 16.25 \\
\hline Percentage of conceptual level responses & 52.37 & 25.66 \\
\hline$n$ of categories completed & 4.11 & 2.25 \\
\hline$n$ of assays required to complete the 1 st class & 36.30 & 38.92 \\
\hline Failure to maintain context & 1.93 & 3.79 \\
\hline \multicolumn{3}{|l|}{ Stroop test } \\
\hline Stroop effect & -1.76 & 10.17 \\
\hline \multicolumn{3}{|c|}{$\begin{array}{l}\text { Note. WASI = Wechsler Abbreviated Scale of Intelligence; } \\
\text { RCFT = Rey Complex Figure Test; WAIS-III = Wechsler Adult } \\
\text { Intelligence Scale, third edition; LNS=Letter-Number Sequencing; } \\
\text { DSF = Digit Span Forward; DSB = Digit Span Backward; } \\
\text { FAS = phonemic verbal fluency test; WCST = Wisconsin Card } \\
\text { Sorting Test. }\end{array}$} \\
\hline
\end{tabular}

The severity of OCS in the symmetry/ordering dimension correlated significantly with impaired attentional control only, as measured by errors of omission on the go/no-go task. The severity of OCS in the hoarding dimension was found to correlate positively with the score on the WASI Matrix Reasoning subtest, indicating better visual analysis skills and logical reasoning. In addition, the OCD patients presenting the hoarding dimension performed more poorly on the WCST, specifically in terms of the "learning to learn" score. These discrepant results suggest that, on more complex tasks, such as the WCST, in which the subject must employ various executive functions, OCD patients do not have sufficient cognitive flexibility or cognitive set-shifting ability and present attentional deficits, manifesting as longer times to complete the test (Sucolotti, 2007). This also supports the idea that the evaluation of executive function requires the use of multiple techniques that focus on various aspects different components of executive functioning, given that deficits in executive function can be selective (Drake \& Torralba, 2007).

One intriguing result of the present study is that there were no significant differences on the WCST for any of the DY-BOCS dimensions except hoarding. The WCST is a complex test that requires, from the point of view of executive functioning, regulation and control of its various components (Coutinho, Miotto, Lucia, \& Scaff, 2009). This suggests a distinct operation of the hoarding dimension, supporting the hypothesis that hoarding is a dimension with unique characteristics or even a separate disorder, distinct from OCD (Cordioli, 2014).

Our results are preliminary and, although they allowed us to associate OCD with impairment of executive functions according to the severity of specific dimensions, it was not possible to construct an executive function profile for each OCS dimension. This is primarily due to the fact that most of our patients presented more than one OCS dimension. Our study has other limitations, such as the small sample size, the lack of a control group and the difficulty in obtaining unbiased information from patients regarding medical treatment. The small sample size may be a bias of this study, especially in relation to the large number of correlations performed. Therefore, our results are preliminary and exploratory. In addition, the neuropsychological evaluation of executive functions itself presents difficulties, because there is no single, standardized instrument that can evaluate all executive functions.

Despite these limitations, our results suggest that specific executive functions are associated with specific OCS dimensions. Further studies are warranted in order to investigate these aspects. In addition, it would be interesting to evaluate executive function using not only neuropsychological instruments but also using neuroimaging studies. Such studies might clarify executive function and functional systems involved in the various OCS dimensions.

\section{References}

Abramowitz, J.S., Deacon, B.J. (2006). Psychometric properties and construct validity of the Obsessive-Compulsive Inventory-Revised: Replication and extension with a clinical sample. Journal of Anxiety Disorders, 20(8), 1016-1035. 
Pedron, A. C., Ferrão, Y. A., Gurgel, L. G., \& Reppold, C. T. (2015). Executive Function and OCD.

American Psychiatric Association. (2000). DSM IV-TR: Diagnostic and statistical manual of mental disorders (4th ed. rev.). Washington, DC: American Psychiatry Association.

American Psychiatric Association. (2013). DSM-5: Diagnostic and statistical manual of mental disorders (5th ed.). Washington, DC: American Psychiatry Association.

Bannon, S., Gonsalvez, C. J., Croft, R. J., \& Boyce, P. M. (2006). Executive functions in obsessive-compulsive disorder: State or trait deficits? Australian and New Zealand Journal of Psychiatry, 40(11-12), 1031-1038. doi:10.1111/j.1440-1614.2006.01928.

Bédard, M. J., Joyala, C. C., Godbouta, L., \& Chantal, S. (2009). Executive functions and the obsessive-compulsive disorder: On the importance of subclinical symptoms and other concomitant factors. Archives of Clinical Neuropsychology, 24(6), 585-598. doi:10.1093/arclin/acp052

Connor, A., Franzen, M. D., Sharp, B. (1988). Effects of practice and differential on Stroop performance. International Journal of Clinical Neuropsychology, 10(1), 1-4.

Coutinho, D. G. C., Miotto, E. C., Lucia, M. C. S., \& Scaff, M. (2009). Avaliação da flexibilidade mental em uma amostra de sujeitos adultos com ensino fundamental por meio do Wisconsin Card Sorting Test (WCST). Psicologia Hospitalar, 7(1), 107-117.

Cordioli, A. V. (2014). TOC: Manual de terapia cognitivo-comportamental para o transtorno obsessivo-compulsivo (2nd ed.). Porto Alegre, RS: Artmed.

Cunha, J. A., Trentini, C. M., Argimon, I. L., Oliveira, M. S., Werlang, B. G., \& Prieb, R. G. (2005). Teste Wisconsin de Classificação de Cartas: Manual. São Paulo, SP: Casa do Psicólogo.

Del-Ben, C. M., Vilela, J. A. A., Crippa, J. A. S., Hallak, J. E. C., Labate, C. M., \& Zuardi, A. W. (2001). Confiabilidade da "Entrevista Clínica Estruturada para o DSM-IV - Versão Clínica" traduzida para o português. Revista Brasileira de Psiquiatria, 23(3), 156-159. doi:10.1590/S1516-44462001000300008

Drake, M., \& Torralba, T (2007). Evaluación de las funciones ejecutivas. In D. Burin, M. Drake, \& P. Harris, Evaluación neuropsicológica en adultos (pp. 299-329). Buenos Aires, Argentina: Paidós.

Ettenhofer, M., Hambrick, D., Abeles, N. (2006). Reliability and stability of executive functioning in older adults. Neuropsychology, 20(5), 607-613. doi:10.1037/0894-4105.20.5.607

First, M. B., Spitzer, R. L., Gibbon, M., \& Williams, J. B. W. (1997). Structured clinical interview for DSM-IV Axis-I disorders: Clinical version (SCID-CV). Washington, DC: American Psychiatric Association.

Foa, E. B., Huppert, J. D., Leiberg, S., Langner, R., Kichic, R., Hajcak, G., \& Salkovskis, P. M. (2002). The ObsessiveCompulsive Inventory: Development and validation of a short version. Psychological Assessment, 14(4), 485-496. doi:10.1037/1040-3590.14.4.485
Fontenelle, L. (2001). Aspectos neuropsicológicos do transtorno obsessivo-compulsivo. Revista Brasileira de Psiquiatria, 23(Supl. 2), 27-30. doi:10.1590/S1516-44462001000600009

Golden, C. J. (1978). Stroop color and word test. Wood Dale, IL: Stoelting.

Goodman, W. K., Price, L. H., Rasmussen, S. A., Mazure, C., Fleischmann, R. L., Hill, C. L., Charney, D. S. (1989). The Yale-Brown Obsessive-Compulsive Scale. I. Development, use, and reliability. Archives of General Psychiatry, 46(11), 1006-1011. doi:10.1001/archpsyc.1989.01810110048007

Grafman, J. (1999). Experimental assessment of adult frontal lobe function. In B. L. Miller \& J. L. Cummings (Eds.), The human frontal lobes: Functions and disorders (pp. 321-344). New York, NY: Guilford.

Heck, V. S., Yates, D. B., Poggere, L. C., Tosi, S. M. V. D., Bandeira, D. R., \& Trentini, C. M. (2009). Validação dos subtestes verbais da versão de adaptação da WASI. Avaliação Psicológica, 8(1), 33-42.

Iverson,G.L.(2001).InterpretingchangeontheWAIS-III/WMS-III in clinical samples. Archives of Clinical Neuropsychology, 16(2), 183-191. doi:10.1016/S0887-6177(00)00060-3

Jang, J. W., Kim, H. S., Ha, T. H., Shin, N. Y., Kang, D. H., Choi, J., ... Kwon, J. S. (2010). Nonverbal memory and organizational dysfunctions are related with distinct symptom dimensions in obsessive-compulsive disorder. Psychiatry Research, 180(2-3), 93-98. doi:10.1016/j.psychres.2010.04.016

Kim, M. S., Jang, K. M., \& Kim, B. N. (2009). The neuropsychological profile of a subclinical obsessive-compulsive sample. Journal of the International Neuropsychological Society, 15(2), 286-290. doi:10.1017/S1355617709090213

Landeros-Weisenberger, A., Bloch, M. H., Kelmendi, B., Wegner, R., Nudel, J., Dombrowski, P., ... Coric, V. (2010). Dimensional predictors of response to SRI pharmacotherapy in obsessive-compulsive disorder. Journal of Affective Disorders, 12l(1-2), 175-179. doi:10.1016/j.jad.2009.06.010

Langenecker, S., Zubieta, J., Young, E., Akil, H., Nielson, K. (2007). A task to manipulate attentional load, set-shifting, and inhibitory control: convergent validity and test-retest reliability of the Parametric Go/No-Go Test. Journal of Clinical and Experimental Neuropsychology, 29(8), 842-853.

Lawrence, N. S., Wooderson, S., Mataix-Cols, D., David, R., Speckens, A., \& Phillips, M. L. (2006). Decision making and set shifting impairments are associated with distinct symptom dimensions in obsessive-compulsive disorder. Neuropsychology, 20(4), 409-419. doi:10.1037/0894-4105.20.4.409

Lewin, A. B., Larson, M. J., Park, J. M., McGuire, J. F., Murphy, T. K., \& Storch, E. A. (2014). Neuropsychological functioning in youth with obsessive compulsive disorder: An examination of executive function and memory impairment. Psychiatry Research, 216(1), 108-115. doi:10.1016/j.psychres.2014.01.014 
Mataix-Cols, D., Frost, R. O., Pertusa, A., Clark, L. A., Saxena, S., Leckman, J. F. ... Wilhelm S. (2010). Hoarding disorder: A new diagnosis for DSM-V? Depression and Anxiety, 27(6), 556-572. doi:10.1002/da.20693

Mataix-Cols, D., Wooderson, S., Lawrence, N., Brammer, M. J., Speckens, A., \& Phillips, M. L. (2004). Distinct neural correlates of washing, checking, and hoarding symptom dimensions in obsessive-compulsive disorder. Archives of General Psychiatry, 61(6), 564-576. doi:10.1001/archpsyc.61.6.564

Menezes, A., Dias, N. M., \& Seabra, A. G. (2011). Disfunção executiva no transtorno obsessivo-compulsivo e na Síndrome de Tourette. Cuadernos de Neuropsicología, 5(1), 49-65.

Menzies, L., Chamberlain, S. R., Laird, A. R., Thelen, S. M., Sahakian, B. J., \& Bullmore, E. T. (2008). Integrating evidence from neuroimaging and neuropsychological studies of obsessive-compulsive disorder: The orbitofronto-striatal model revisited. Neuroscience and Biobehavioral Reviews, 32(3), 525-549. doi:10.1016/j.neubiorev.2007.09.005

Miguel, E. C., Ferrão, Y. A., Rosário, M. C., Mathis, M. A., Torres, A. R., Fontenelle, L. F.The Brazilian Research Consortium on Obsessive-Compulsive Spectrum Disorders (2008). The Brazilian Research Consortium on Obsessive-Compulsive Spectrum Disorders: Recruitment, assessment instruments, methods for the development of multicenter collaborative studies and preliminary results. Revista Brasileira de Psiquiatria, 30(3), 185-196. doi:10.1590/S1516-44462008000300003

Moritz, S., Meier, B., Kloss, M., Jacobsen, D., Wein, C., Fricke, S., Hand, I. (2002). Dimensional structure of the Yale-Brown Obsessive-Compulsive Scale (Y-BOCS). Psychiatry Research, 109(2), 193-199. doi:10.1016/S0165-1781(02)00012-4

Nascimento, E. (2000). Adaptação e validação do teste WAIS-III para um contexto brasileiro (Unpublished doctoral dissertation). Universidade de Brasília, Brasília-DF, Brazil.

Oliveira, M. S., \& Rigoni, M. S. (2010). Figuras Complexas de Rey: Teste de cópia e reprodução de figuras geométricas complexas. São Paulo, SP: Casa do Psicólogo.

Pena-Garijo, M. J., Ruipérez-Rodríguez, A., \& Barros-Loscertales, A. (2010). Neurobiología del trastorno obsesivo-compulsivo: Aportaciones desde la resonancia magnética funcional. Revista de Neurología, 50(8), 477-485.

Pena, M. C. S., \& Vale, F. A. C. (2010). Sintomas obsessivocompulsivos nas demências. Revista de Psiquiatria Clínica, 37(3), 124-130.
Rauch, S. L., Dougherty, D. D., Shin, L. M., Alpert, N. M., Manzo, P., Leahy, L., ... Jenike, M. A. (1998). Neural correlates of factor-analyzed OCD symptom dimensions: A PET study. CNS Spectrums, 3(7), 37-43. doi:10.1017/S1092852900006167

Roh, K. S., Shin, M. S., Kim, M. S., Ha, T. H., Shin, Y. W., Lee, K. L., \& Kwon, J. S. (2005). Persistent cognitive dysfunction in patients with obsessive-compulsive disorder: A naturalistic study. Psychiatry and Clinical Neurosciences, 59(5), 539-545.

Rosario-Campos, M. C., Miguel, E. C., Quatrano, S., Chacon, P., Ferrão, Y., Findley, D., ... Leckman, J. F. (2006). The Dimensional Yale-Brown Obsessive-Compulsive Scale (DY-BOCS): An instrument for assessing obsessive-compulsive symptom dimensions. Molecular Psychiatry, 11(5), 495-504.

Shigaeff, N., Miotto, E. C., Lucia, M. C. S., \& Scaff, M. (2011). Processos atencionais em idosos saudáveis com alta escolaridade da comunidade da cidade de São Paulo. Psicologia Hospitalar, 9(2), 96-113.

Shin, M. S., Park, S. J., Kim, M. S., Lee, Y. H., Ha, T. H., \& Kwon, J. S. (2004). Deficits of organizational strategy and visual memory in obsessive-compulsive disorder. Neuropsychology, 18(4), 665-672.

Sucolotti, G. O. (2007). A relevância do córtex pré-frontal no transtorno obsessivo compulsivo (Unpublished master's thesis). Pontifícia Universidade Católica do Rio Grande do Sul, Porto Alegre-RS, Brazil.

Tombaugh, T.N., Kozak, J., Rees, L. (1999). Normative data stratified by age and education for two measures of verbal fluency: FAS and animal naming. Archives of Clinical Neuropsychology, 14, 166-177. doi:10.1093/arclin/14.2.167

Tükel, R., Gürvit, H., Ertekin, B. A., Oflaz, S., Ertekin, E., Baran, B., Atalay, F. (2012). Neuropsychological function in obsessive-compulsive disorder. Comprehensive Psychiatry, 53(2), 167-175. doi:10.1016/j.comppsych.2011.03.007

Vandborg, S. K., Hartmann, T. B., Bennedsen, B. E., Pedersen, A. D., \& Thomsen, P. H. (2014). Memory and executive functions in patients with obsessive-compulsive disorder. Cognitive and Behavioral Neurology, 27(1), 8-16. doi:10.1097/WNN.0000000000000021

Wechsler, D. (1997). Wechsler Adult Intelligence Scale (WAIS-III) (3rd ed.). San Antonio, TX: The Psychological Corporation.

Ana Cristina Pedron holds an M.S. in Health Sciences from the Universidade Federal de Ciências da Saúde de Porto Alegre. Ygor Arzeno Ferrão is an Associate Professor of the Universidade Federal de Ciências da Saúde de Porto Alegre. Léia Gonçalves Gurgel is a Ph.D. candidate from the Universidade Federal de Ciências da Saúde de Porto Alegre. Caroline Tozzi Reppold is an Associate Professor I from the Universidade Federal de Ciências da Saúde de Porto Alegre. 
Pedron, A. C., Ferrão, Y. A., Gurgel, L. G., \& Reppold, C. T. (2015). Executive Function and OCD.

Received: July 21, 2014

1st Revision: Nov. 24, 2014

2nd Revision: Jan. 16, 2015

Approved: Jan. 26, 2015

How to cite this article:

Pedron, A. C., Ferrão, Y. A., Gurgel, L. G., \& Reppold, C. T. (2015). Relations between executive functions and different symptomatic dimensions in obsessive compulsive disorder. Paidéia (Ribeirão Preto), 25(61), 229-239. doi:10.1590/1982-43272561201511 